\title{
LA CLIOMETRIA: \\ UNA VISION NORTEAMERICANA *
}

\author{
JEFFREY G. WILLIAMSON \\ Harvard University
}

Me siento honrado de contarme entre los participantes en la tercera reunión de Historia Cuantitativa española. Las ponencias han sido invariablemente de gran calidad, y la discusión, animada. De hecho se percibe una cmoción en el ambiente como yo no he sentido desde los años sesenta, cuando los cliómetras americanos estaban iniciando lo que resultó ser una profunda revolución intelectual. Me parece por ello especialmente apropiado compartir con vosotros algunas consideraciones sobre el lugar que ha ocupado la cliometría en las universidades norteamericanas y hacia dónde parece ahora encaminarse. Empezaré por el principio.

$$
* * *
$$

A finales de los años cincuenta, los exploradores cliométricos comenzaban a desbrozar la maleza cualitativa, estableciendo sus asentamientos con estruendoso entusiasmo. Como es típico de exploradores y conquistadores, los cliómetras eran jóvenes, exclusivistas, altivos, y pendencieros. Valoraban las virtudes de la econometría y de la teoría, y buscaban dogmas históricos que pudieran desacreditarse fácilmente con los nuevos métodos aprendidos en los programas para graduados en economía. Estos primeros asentamientos cliométricos estaban poco densamente poblados, pero pronto despertaron interés. Los economistas los apoyaban, porque les permitían ejercer influencia sobre otro campo ap'icado. Los historiadores trataban de repeler a los cliómetras porque los bárbaros invasores hablaban un lenguaje de ciencia social que sonaba extrañamente en sus oídos humanistas.

La cliometría ha madurado sin duda. A los primeros pioneros cuantitativistas (Lance Davis, Dick Easterlin, Bob Gallman, John Hughes, Stan Lebergott, Doug North, Bill Parker, y Nate Rosenberg) se unió una segunda generación de aventureros aún más técnicos (Paul David, Stan Engerman, Al

* Conferencia de clausura del III Seminario de Historia Económica Cuantitativa, Alcalá, diciembre 1988 . 
Fishlow, Bob Fogel, Peter Temin, y yo mismo). Como todas las poblaciones de frontera, los pioneros tenían una alta tasa de fecundidad, y produjeron un gran número de discípulos que constituyeron la tercera generación (Bob Allen, Claudia Goldin, Knick Harley, Peter Lindert, Don MacCloskey, Joel Mokyr, Richard Sutch, y Gavin Wright). La cuarta generación se estrenó a finales de los setenta, y las universidades norteamericanas han venido produciendo nuevos cliómetras a ritmo rápido desde entonces, de modo que casi la mitad de los participantes en la reunión de la Asociación de Cliometría de Miami, Ohio, en la primavera de 1988, eran aún estudiantes o recién doctorados.

Como era de esperar, los exploradores de las primeras generaciones comenzaron reconociendo el Nuevo Mundo por América del Norte. Pero más recientemente, sin embargo, los cliómetras norteamericanos han empezado a explorar nuevas áreas. Entre los de la segunda generación, Al Fishlow ha vuelto su atención hacia América Latina, Stan Engerman hacia el Caribe, Bob Fogel ha trabajado sobre comparaciones internacionales de mortalidad, y yo llevo trabajando sobre el Japón Meiji y la revolución industrial inglesa desde hace más de diez años. En la tetcera generación, sólo Claúdia Goldin, Richard Sutch y Gavin Wright trabajan todavía sobre América del Norte. Y es significativo que los encuentros de la Sociedad Cliométrica se hayan hecho internacionales en 1985 y el Segundo Congreso vaya a celebrarse en Santander en junio de 1989.

La consecuencia es clara: la cliometría se ha extendido ampliamente desde que, hace tres decenios, inició sus pasos con norteamericanos que trabajaban sobre problemas norteamericanos. Es más, mucha de la investigación de interés que hoy se hace en las universidades norteamericanas no está centrada en temas de América del Norte.

La cliometría ha madurado también en otros aspectos. En el pasado, los cliómetras norteamericanos se volvían a la historiografía tradicional en busca de temas. ¿Era eficiente la esclavitud en el Sur? ¿Fue indispensable el ferrocarril? ¿Tenían razones los agricultores del Medio Oeste para su descontento? ¿Estimuló la Guerra de Secesión la industrialización? En cambio ahora los cliómetras se vuelven más hacia la economía en busca de problemas. ¿Cuáles son los determinantes de la acumulación? ¿Conlleva desigualdad la industrialización? ¿Es eficiente la agricultura tradicional? ¿Qué consecuencias ha tenido la integración mundial de los mercados de capitales en los últimos cien años? ¿Quién repudia las deudas estatales y por qué? ¿Qué hacen los patronos? ¿Qué determina las alzas y luego las bajas seculares observadas en la fertilidad? ¿Por qué disminuye la productividad? ¿Cuáles son los costes derivados de las distorsiones institucionales en los mercados de trabajo y de capital? ¿Cómo se explica la convergencia de los países rezagados hacia el 
nivel de los adelantados, y por qué algunas economías de la Periferia (como España) tardan tanto en converger? ¿Cómo responden las economías pequeñas (como España) a los cambios bruscos de los precios internacionales? ¿Cómo se explican las macro-inestabilidades y qué consecuencias tienen para las economías de la Periferia (como España) las depresiones emanadas del Centro? Me imagino que este desplazamiento del interés se debe simplemente a que la mayor parte de los cliómetras norteamericanos han estudiado en departamentos de economía y en ellos residen.

Los cliómetras norteamericanos están perdiendo interés en estudios de países y en su lugar cada vez hacen más historia económica comparada. ¿Cómo si no podremos convencer a nuestros compañeros economistas de la relevancia de nuestros descubrimientos empíricos? Una muestra de un solo caso difícilmente convencerá a un economista que busca «teoremas generales".

Por último, otro signo infalible de madurez es el esfuerzo de los cliómetras para educar a los economistas y mostrar que los descubrimientos cliométricos han contribuido a enriquecer el pensamiento económico. Por ejemplo, en las reuniones de 1984 y 1986 de la American Economic Association hubo sesiones dedicadas exclusivamente a las contribuciones de la historia económica a la economía. Y para poner otro ejemplo, los miembros de la cuarta generación cliométrica hicieron un libro en 1987 titulado The Future of Economic History donde se trataba este mismo tema.

Ha llegado así el momento de hacer inventario. ¿A qué parece probable que dediquen sus esfuerzos los cliómetras norteamericanos en el futuro? $\mathrm{Y}$ ¿deben los cliómetras españoles seguir su ejemplo?

Empecemos con el problema de la acumulación y la desigualdad. Estos temas ocupaban el centro de la atención de economistas e historiadores económicos hasta que el de la inestabilidad macroeconómica los sustituyó tras los choques de la OPEP. Mucho hemos aprendido sobre la desigualdad. Hemos trazado la curva de Kuznets a lo largo de más de dos siglos de historia de Estados Unidos y Gran Bretaña, y hemos empezado a comprender los determinantes históricos de la desigualdad. Además, el debate sobre los niveles de vida en la revolución industrial ha progresado más allá de la discusión inicial entre Hartwell y Hobsbawm a finales de los años cincuenta. Quizá lo más importante sea que a partir de la evidencia en estos dos países podemos rechazar categóricamente el postulado smithiano sobre la alternativa crecimiento-igualdad: el aumento de la desigualdad no fue un determinante importante de las tasas de acumulación en ascenso del siglo XIX, especialmente 
si tomamos en consideración el capital humano. Hemos aprendido, además, que la mayor parte de los debates históricos sobre política económica tenían menos que ver con cuestiones de asignación y crecimiento que con problemas de distribución.

¿Qué queda entonces por hacer? En primer lugar, agrandar la muestra histórica. Los datos recientes nos permiten esperar una gran variedad de experiencias en materia de desigualdad en la evolución de las distintas naciones desde el subdesarrollo agrario a la madurez industrial. Necesitamos más evidencia histórica para conocer cuáles son las condiciones y políticas que favorecen el crecimiento sin igualdad y el estancamiento de los salarios reales en los comienzos de la industrialización. Aquí habría que incluir, naturalmente, la experiencia de España desde fines del siglo xix. Tenemos, además, abundante evidencia documental de un progresivo aumento de la igualdad en Europa Occidental y América del Norte en el medio siglo siguiente a la Primera Guerra Mundial. ¿Cuáles fueron las fuerzas comunes que rebajaron la desigualdad a lo largo de la curva de Kuznets en Gran Bretaña, Alemania, los Países Bajos, Escandinavia y los Estados Unidos? ¿Está España incluida aquí? En segundo lugar, debemos plantearnos los contrafactuales apropiados. El debate sobre el nivel de vida, por ejemplo, se ha centrado casi exclusivamente en la pregunta "¿qué ocurrió?" Apenas hemos tocado, en cambio, las cuestiones más importantes de «¿por qué ocurrió?» y « ¿había alternativas posibles?» Esto es válido para la revolución industrial inglesa y supongo que también lo es para la española.

La clave de la acumulación aún se nos escapa. ¿Constituye el volumen de ahorro interno un factor limitativo? ¿Es la demanda de inversión un estímulo? En parte la respuesta depende del grado de apertura de la economía que estemos estudiando. Sobre la base de unas pocas economías europeas y norteamericanas, parece que, en tiempos «normales», los mercados financieros internaciona'es estaban tan bien integrados a principios del siglo xviII como a finales del xx. ¿Resulta de esto que las tasas de acumulación venían determinadas por la demanda de inversión mientras que el ahorro interno simplemente influía en el volumen de las importaciones de capital? Depende. En primer lugar, si bien para las economías que se encontraban bien integradas en los mercados financieros internacionales el ritmo de acumulación no estaría forzosamente limitado por la magnitud del ahorro interno, en ocasiones este ritmo sí se vería frenado por coyunturas de escasez en los mercados mundia'es de capital. Necesitamos conocer mejor el impacto de tales fluctuaciones del mercado financiero internacional sobre las economías nacionales, España incluida, cuya mejor ilustración quizá sean los «ciclos largos» (o de Kuznets) a partir de mediados del xix. En segundo lugar, las lecciones históricas derivadas de nuestro conocimiento de una pequeña muestra de países europeos 
y americanos del Centro nada nos dice sobre todas las demás economías situadas en la Periferia cuyo grado de apertura no está aún establecido. ¿Estaban los países periféricos menos integrados en el mercado financiero mundial, y tenían por ello que depender en mayor medida del ahorro interno? ¿Qué papel representa España en este escenario? En tercer lugar, todas estas lecciones nada nos dicen sobre los tiempos «anormales» tales como las guerras napoleónicas, la Gran Depresión, la II Guerra Mundial y su posguerra, períodos durante los cua'es tuvieron lugar revoluciones industriales importantes. En cuarto lugar, ¿cómo se explica la aparente asimetría de los mercados de factores en el siglo xix para algunos países pequeños, como por ejemplo Irlanda? Es decir, ¿cómo se explica la coexistencia de una masiva emigración de trabajadores irlandeses desde mediados de siglo con una total ausencia de flujos de capital hacia un país donde el trabajo era tan barato?

¿Cuáles fueron los determinantes de la acumulación en los países coyuntural o estructuralmente excluidos de los mercados mundiales de capital? En busca de una respuesta parece llegado el momento de que los historiadores económicos rexaminen su visión de la austeridad, el ahorro y la acumulación basada en un solo activo. Es mejor pensar en términos de un abanico de activos, estructurados en carteras. Las finalidades del ahorro pueden incluir la acumulación de deuda pública, deuda exterior, activos irreproducibles, plusvalias de capital (incluidas las alzas de los bienes raíces), capital físico, etc. Si bien es cierto que la demanda de inversión influirá en la contribución del ahorro a la formación de capital, también lo es que cualquier cambio exógeno en la oferta de otras formas de acumulación tenderá a ejercer un efecto expulsión (crotvding out) sobre la formación de capital. Ambas fuerzas (demanda de inversión y efecto expulsión) tendrán probablemente más importancia que el puro ahorro para explicar los distintos tipos históricos de crecimiento, incluso en los casos de economías poco integradas en los mercados mundiales. Sea como fuere, necesitamos saber más acerca de los determinantes de las tasas de ahorro, incluyendo el papel de las instituciones financieras, la distribución de la renta, y las variables demográficas. Aunque sabemos ya bastante sobre países grandes, como Estados Unidos, sabemos poco sobre países pequeños como España.

Debiera añadir, sin embargo, que no está claro que los términos «ahorro agregado interno» $y$ «demanda agregada de inversión» puedan siquiera aplicarse a la historia económica de muchos países en desarrollo. Cuando los mercados internos de capital estaban muy segmentados y las empresas se financiaban en gran parte con fondos generados internamente para sus inversiones a largo plazo, la acumulación debe haberse visto frenada y los ahorradores potenciales faltos de empleos donde colocar sus fondos. Necesitamos saber mucho más acerca del funcionamiento de los mercados de capital, sobre 
el impacto que tenían sus distorsiones, y sobre los efectos de las innovaciones institucionales destinadas a superar los efectos de esas ditorsiones. De éstas, una de las más importantes estuvo relacionada con la acumulación de capital social fijo. ¿Por qué fue tan bajo el nivel de formación de capital social fijo en las ciudades británicas durante la mayor parte del siglo xix? ¿Por qué siguió Gran Bretaña una estrategia de «miseria urbana», al contrario del Tercer Mundo en el siglo xx? ¿Cómo encaja España en el cuadro?

Pasemos de la acumulación al progreso técnico. Los historiadores económicos han insistido en las ventajas de los rezagados. Quizá el caso más conocido sea el de Alexander Gerschenkron, que dijo que los rezagados seguirían casi indefectiblemente una vía de desarrollo distinta de la de los adelantados. Gerschenkron estableció seis principios, y la base explicativa de la mayoría de ellos era que para los rezagados sería mayor el desfase entre la técnica media interna y la mejor técnica extranjera, por lo cual las ganancias derivadas de la transferencia tecnológica serían muy grandes. Este plausible argumento sugirió lo que se ha dado en llamar la hipótesis de la convergencia, a saber: que cuanto más atrasado el país, más probable es que su crecimiento supere al de los adelantados.

Tras estar en candelero en los años cincuenta y sesenta, la hipótesis de la convergencia cayó en el olvido durante unos decenios, pero reapareció en un artículo de Baumol (1986), motivado sin duda por la desaceleración de la productividad en Europa y Norteamérica y un acortamiento de distancias por parte de la ribera asiática del Pacífico (quizá una nueva versión de lo ocurrido a finales del XIX, cuando Inglaterra perdió velocidad y se vio alcanzada por Alemania y USA). Baumol confirmaba la correlación histórica entre el crecimiento del PNB por habitante (en el período 1870-1879) y el atraso inicial (PNB por habitante en 1870), hasta el extremo de afirmar que, siendo tan clara la correlación, las diferencias nacionales de cultura, instituciones, y política no podían haber pesado mucho. Lo único importante para Baumol era el desfase entre el nivel técnico interno y la frontera técnica exterior. Los críticos han alegado que Baumol había simplificado su caso restringiendo la muestra a sólo 16 países que estaban todos industrializados en 1979. España, por ejemplo, no estaba incluida en la muestra y no confirma la tesis. ¿Por qué? Si hay un problema en la historia económica de España que debe informar su actual política económica es éste. Por ejemplo: ¿por qué creció tan poco durante los años cuarenta, mientras América Latina, que también fue neutral durante la guerra, creció tanto?

Tras el trabajo de Baumol han aparecido una serie de artículos que intentan afinar la discusión y ampliar la muestra. El hallazgo más interesante, sin embargo, es la clara evolución en el "coeficiente de alcance» desde 1870 . A través de cuatro grandes períodos - 1870-1890, 1890-1913, 1913-1938 y 
1950-1983 - el coeficiente basado en el desfase inicial de productividad aumenta fuertemente, incluso durante los años entre guerras. Parece, por tanto, que la economía mundial ha ido mejorando su capacidad para transferir la tecnología de punta a los rezagados: el mismo desfase entre adelantado y rezagado produce una convergencia más rápida en la actualidad que hace un siglo. La explicación reside probablemente en la mayor integración de los mercados mundiales de mercancías y factores, y en el desarrollo de instituciones que han reducido drásticamente los costes de transferencia tecnológica.

Me parece que los historiadores económicos están mejor equipados para identificar exactamente cómo y por qué tiene lugar la convergencia. Me parece también que España ofrece un excelente campo para estudiar este proceso. ¿Por qué tardó tanto este rezagado en beneficiarse del desfase?

Volvamos ahora nuestra atención a la demografía, una de las áreas de investigación de mayor actividad e influencia de las practicadas por historiadores económicos durante el último decenio. Aquí los principales problemas son entender las relaciones entre población y economía en las sociedades preindustriales, y las transiciones demográficas post-industriales. La demografía histórica ha hecho contribuciones en este campo que rivalizan en importancia con las de la demografía a secas. Nuestros conocimientos acerca de los determinantes de la fertilidad y la mortalidad se han visto profundamente influidos por la investigación histórica. El problema clave para los científicos sociales que trabajan temas demográficos es mejorar nuestra comprensión de la interdependencia entre demografía y economía. No se trata sólo de comprender cómo influye la economía en la demografía; igualmente importante es desentrañar la relación inversa. Los cliómetras se han ocupado de ambas cuestiones. La historia nos ha enseñado mucho acerca del impacto distributivo de la emigración y los baby booms, sobre los impactos en la inversión de las crisis demográficas, sobre la influencia del tamaño de las familias sobre el ahorro y la acumulación, sobre los problemas de absorción en el mercado laboral, etc. $\mathrm{Mi}$ idea es que el futuro de este campo no está tanto en los determinantes del cambio demográfico cuanto en la respuesta económica a este cambio.

¿Qué sabemos sobre la evolución de los mercados de trabajo? En el pasado tendiamos a tomar partido en este asunto: los puristas neoclásicos sólo veían evidencias de la eficiencia del mercado, mientras sus críticos no veían más que segmentación, fragmentación y salarios fijados institucionalmente. Yo creo que ahora ya estamos dispuestos a contrastar empíricamente ambas posturas. Consideremos las siguientes cuestiones; ¿cuándo aparecen los mercados de trabajo integrados? Si la aparición de mercados laborales eficientes ha sido lenta y ardua, y su estructura se viene abajo durante pongamos, las 
revoluciones industriales, ¿qué impacto económico tienen estos fallos? A propósito de esto: ¿cómo se explica la persistencia de grandes diferenciales salariales entre el campo y la ciudad? ¿Se trata de un fallo del mercado, o de un equilibrio que refleja diferenciales de eficiencia o salarios compensatorios, estos últimos bien conocidos en la teoría del desarrollo por los estudios de Harris y Todaro sobre el paro urbano? Hay indicios de que los mercados de trabajo y capital tuvieron fallos durante la revolución industrial inglesa, especialmente en las décadas de 1830 y 1850: se dio un exceso de trabajo y de capital en el campo inglés, con un alto coste en términos de renta no producida. También hay indicios del mismo fenómeno en Estados Unidos, quizá hasta la década de 1930. ¿Ocurriría esto también en España o se evitaron aquí estos problemas?

No faltan por tanto problemas en que puedan ocuparse los historiadores laborales en el futuro. Y he aquí unos cuantos más: cha venido la demanda de trabajo cualificado en el pasado determinada por la técnica, o han sido los perfiles de empleo siempre maleables? ¿Eran el capital físico y el humano sustituibles en el siglo pasado y, en caso afirmativo, cómo se explica que hoy sean complementarios? Por añadidura, hace ya casi veinte años que los historiadores económicos estudiaron sistemáticamente las grandes migraciones, los problemas de absorción de emigrantes, y las políticas de restricciones a la migración, y éstos son temas de gran actualidad que requieren nuevas orientaciones de la historia. Tampoco estamos estudiando a fondo la emigración a la ciudad y los problemas de absorción que conlleva, incluyendo, como ya vimos, las consecuencias que tuvo la desinversión en capital fijo urbano en términos de hacinamiento y miseria urbana, tema de rabiosa actualidad en el Tercer Mundo que también se beneficiaría de las enseñanzas de la historia. Por último, ¿qué sabemos acerca de los determinantes del capital humano y sus efectos? Con la aparición del «residuo» en los ejercicios sobre las fuentes del crecimiento en los años sesenta empezamos a darnos cuenta de cuán crucial tiene que ser la acumulación de capital humano en el proceso general de crecimiento. Empezamos también a sospechar que las economías que habian prestado atención a la educación institucional y laboral, a la salud pública y a otras formas de formación de capital humano habían tendido a producir distribuciones más igualitarias. Así, la escasa inversión en educación en la Inglaterra anterior a 1870 produjo altos rendimientos a la alfabetización, rentas extraordinarias para la aristocracia laboral de Hobsbawm, desigualdad creciente y, es de suponer, trabas a la industrialización. En la América Latina del sig.o xx parece ocurrir algo parecido. En contraste, el Pacífico asiático, encabezado por Japón, tiene una historia diferente, con inversiones relativamente altas en capital humano y distribuciones más igualitarias. Si bien está claro que la acumulación de capital humano facilita la consecución de 
distribuciones igualitarias, aún no sabemos si las distribuciones igualitarias facilitan también la acumulación de capital y la industrialización. Los cliómetras no han mostrado gran interés en esta segunda cuestión, que, sin embargo, exige una respuesta. ¿Dónde encaja España, en el modelo latinoamericano o en el asiático?

Enfoquemos ahora los temas comerciales. Debido a la tradición keynesiana, la historia tradicional ha estado dominada, hasta muy recientemente, por los desplazamientos exógenos de la demanda mundial. Donde más credibilidad alcanzaba esta postura era cuando se veía al comercio como «motor del crecimiento». Es cierto que comercio y crecimiento han ido altamente correlacionados desde la Inglaterra de finales del xvirI hasta la reciente experiencia del Tercer Mundo. Pero ¿podemos pasar de la correlación a la inferencia causal de que el comercio fue el motor del crecimiento? No podemos. La correlación no nos dice si el crecimiento del comercio venía causado por una oferta interna elástica a largo plazo o por desplazamientos favorables de la demanda externa. Si se daba el primer caso, el mérito corresponde al país en cuestión. Si el segundo, el país debería atribuir el mérito a su fortuna. Este debate está estrechamente ligado a la cuestión del impacto que tuvo sobre la economía de España la pérdida de sus colonias americanas. ¿Cómo afectó esto a la actuación de la economía española en el xix? En el caso inglés, después de todo, la pérdida de las colonias americanas no pareció afectar gran cosa a la revolución industrial.

Recientemente se ha tendido a quitar importancia a la tesis de que el comercio es un motor de crecimiento movido por desplazamientos en la demanda, pero no encuentro en toda la bibliografía histórica un solo intento sistemático de separar el papel de los desplazamientos de la oferta interna del de los desplazamientos de las condiciones externas en el estímulo (o estrangulamiento) de la exportación y el crecimiento. $Y$, a juzgar por los debates que se entablan en el Banco Mundial y el FMI, una respuesta a este problema nos está haciendo mucha falta.

Mientras que todo el mundo piensa en los desplazamientos exógenos de la demanda mundial, nadie se acuerda de la elasticidad-precio de la función de demanda. Esto queda muy claro en los debates sobre el papel histórico de la agricultura. Aceleró la industrialización el aumento de la productividad agrícola? Esta es una vieja pregunta en historia económica, que ha sido puesta de nuevo sobre el tapete por el magisterio de W. Arthur Lewis. En sus conferencias del ciclo Janeway, en Princeton, Lewis se preguntaba: ¿Por qué no se industrializó antes el Tercer Mundo? Su respuesta fue que el atraso agrícola de estos países implicó un mercado estrecho para la manufactura y un excedente insuficiente para la acumulación. El argumento de Lewis 
puede resultar plausible, pero ¿es relevante empíricamente para, por ejemplo, un país como España a finales del siglo XIX?

En busca de respuestas a estas preguntas los historiadores económicos no dedican a las elasticidades del comercio el tiempo que merecen. Si una economía está relativamente cerrada al comercio, las mejoras en la productividad agricola sin duda estimulan la industrialización, ya que al tiempo que hacen aumentar el volumen producido hacen bajar los precios agrícolas en proporción aún mayor, ya que la elasticidad de demanda es menor que la unidad. El valor del producto marginal desciende, lo cual hace que el trabajo y demás factores abandonen el sector agrícola. La industria se beneficia de esos factores baratos. En cambio, si la economía es relativamente abierta, las alzas en la productividad agraria debieran perjudicar a la industrialización, ya que reforzarían la ventaja comparativa de la agricultura. Es decir, observaríamos una desindustrialización y un caso del «mal holandés». Necesitamos un mayor conocimiento sobre el papel del comercio y de cómo puede contribuir a explicar la variedad de experiencias históricas que se han observado. Hay, además, toda una serie de debates tradicionales que giran en torno a las elasticidades comerciales, de los que es un ejemplo excelente el relativo a la abolición de las Leyes de Cereales en Inglaterra. Es curioso que tales cuestiones hayan sido relativamente ignoradas por los cliómetras; sospecho que se ocuparán más de ellas en el futuro.

Me queda por decir una palabra sobre la historia macroeconómica, uno de nuestros mejores caballos de batalla. He dicho poco, sobre todo, porque ocupa una posición privilegiada que le asegura un brillante futuro, ya que un buen número de economistas consideran hoy a la macroeconomía como un tema esencia'mente histórico. La Gran Depresión y sus causas han tenido un papel crucial en el desarrollo de la historia macroeconómica durante aproximadamente el último decenio. Pero no se ha limitado a eso la historia macroeconómica. Sus incursiones han incluido las tendencias de los salarios reales y los precios relativos durante la Revolución de los Precios en el siglo xvi, guerras y efecto expulsión, la hipótesis keynesiana del desfase de salarios, la evolución de la curva de Phillips, ciclos, hiperinflación, el funcionamiento del Patrón Oro, la paradoja de Gibson, paro, deuda, repudios. La lista es lo bastante larga como para augurar un feliz futuro a la historia macroeconómica, incluida la española.

Aunque algunos de los que me escuchan ya tendrán bastante quehacer en los próximos años escribiendo la versión cliométrica de la historia económica de España, no puedo resistir la tentación de señalar un área que tiene aún mayor necesidad de nuestra atención. La cliometría parece haber dividido 
el mundo en tres: América del Norte, Gran Bretaña y Europa Continental. Muy bien para Occidente, pero ¿qué pasa con Oriente y todo lo demás? ¿Qué pasa con América Latina, Afrića Negra, Oriente Medio, India, China, Japón? En mi opinión, el trabajo más apasionante de los cliómetros en el futuro estudiará la experiencia del Tercer Mundo en los últimos cien años.

Muchos analistas han rechazado las lecciones de la historia del Centro como irrelevantes para entender la evolución de las economías de la Periferia, pero disponían de muy poca buena historia económica del Tercer Mundo de la que echar mano en los debates sobre política económica que tuvieron lugar en las décadas de 1950 y 1960 . Unos pocos precursores se replantearon todo esto en los setenta, y sus contribuciones han sido aún más impresionantes en los ochenta. Algunas han tenido ya profundo impacto sobre las políticas y los paradigmas de desarrollo del Tercer Mundo. Voy a enumerar algunos de estos logros.

Nuestras visiones del desarrollo, incluyendo la relevancia del modelo de crecimiento dualista, se han visto radicalmente alteradas gracias a varios importantes estudios sobre el Japón Tokugawa y Meiji; nuestro conocimiento sobre la economía del hambre ha mejorado considerablemente al estudiar la India británica; hoy conocemos mejor las respuestas boserupianas al aumento de densidad demográfica con el estudio de la historia de Asia y Africa; nuestra comprensión del cambio institucional y técnico inducido se ha enriquecido con los estudios sobre historia de Tailandia, Egipto y Japón; los estudios sobre la historia del Tercer Mundo han rechazado definitivamente la creencia de que los campesinos son irracionales; la reciente crisis financiera ha generado trabajos muy serios sobre f'ujos de capital, deuda y repudios en la periferia en desarrollo; la lista podría continuar.

De importancia aún mayor, en mi opinión, es que hoy comprendemos mejor los efectos de la Gran Depresión en la Periferia. Nuestra comprensión del funcionamiento de los mercados mundiales y su impacto en los exportadores de materias primas se ha enriquecido con los estudios de la economía de entreguerras, pero aún más importante es la mejora en nuestra comprensión de cómo respondió el Tercer Mundo a la depresión mundial. América Latina respondió a la crisis con precoces experimentos de corte keynesiano mucho antes de que estas políticas se popularizaran en los países industriales. También sabemos hoy más sobre sustitución de importaciones y estructuralismo gracias a los esudios sobre América Latina en los años treinta y cuarenta. También conocemos mejor el coste de tales políticas cuando duran demasiado, como ocurrió durante el gran crecimiento de los cincuenta, los sesenta y los primeros setenta. Los historiadores económicos, por tanto, han tenido un papel esencial en el estudio de los costes y los beneficios de las políticas de aislamiento y apertura en el Tercer Mundo. 
La historia económica del Tercer Mundo tiene su porvenir en temas de este tipo, y, en mi opinión, los cliómetras debieran dedicar un mayor esfuerzo a esta región. El nexo natural para los cliómetras españoles es América Latina. No tengo idea de si esta nueva ola de investigación cliométrica correrá a cargo de ciudadanos del Tercer Mundo, pero sí sé que tenemos la responsabilidad de formarles. La historia económica del Tercer Mundo es demasiado importante y relevante a las cuestiones políticas actuales para dejársela a los no-economistas.

¿Se permite a un viejo cliómetra norteamericano despedirse de sus jóvenes colegas españoles con un consejo? En nuestros años mozos los cliómetras norteamericanos perdimos demasiada energía tratando de escribir historia revisionista y arremeter contra la historia tradicional. En la madurez nos hemos dado cuenta de que es mucho más importante educar a los economistas que revisar la historia tradicional. He aquí mi consejo: madurad lo antes posible. Tratad de comunicar con los economistas seleccionando temas que les interesen, e intentad publicar en sus revistas.

\section{(Trad.: Gabriel Tortelia y Clara Eugenia NúÑEz.)}

\section{REFERENCIAS}

BAUMOL, W. J. (1986): «Productivity Growth, Convergence, and Welfare: What the Long Run Data Show», American Economic Review (díciembre), pp. 1072-1085.

Field, A. (1987): The Future of Economic History, Boston: Kluwer-Nijhoff. 